\title{
Paravertebral foramen screw fixation for posterior cervical spine fusion: biomechanical study and description of a novel technique
}

\author{
Satoshi Maki, MD, PhD, ${ }^{1}$ Masaaki Aramomi, MD, PhD, ${ }^{2}$ Yusuke Matsuura, MD, PhD, ${ }^{1}$ \\ Takeo Furuya, MD, PhD, ${ }^{1}$ Mitsutoshi Ota, MD, PhD, ${ }^{1}$ Yasushi lijima, MD, ${ }^{1}$ Junya Saito, MD, ${ }^{1}$ \\ Takane Suzuki, MD, PhD, ${ }^{1}$ Chikato Mannoji, MD, PhD, ${ }^{2}$ Kazuhisa Takahashi, MD, PhD, ${ }^{1}$ \\ Masashi Yamazaki, MD, PhD, ${ }^{3}$ and Masao Koda, MD, $\mathrm{PhD}^{1}$ \\ 'Department of Orthopaedic Surgery, Chiba University Graduate School of Medicine, Chiba; ${ }^{2}$ Department of Orthopaedic \\ Surgery, Teikyo University Chiba Medical Center, Ichihara; and ${ }^{3}$ Department of Orthopaedic Surgery, Faculty of Medicine, \\ University of Tsukuba, Japan
}

OBJECTIVE Fusion surgery with instrumentation is a widely accepted treatment for cervical spine pathologies. The authors propose a novel technique for subaxial cervical fusion surgery using paravertebral foramen screws (PVFS). The authors consider that PVFS have equal or greater biomechanical strength than lateral mass screws (LMS). The authors' goals of this study were to conduct a biomechanical study of PVFS, to investigate the suitability of PVFS as salvage fixation for failed LMS, and to describe this novel technique.

METHODS The authors harvested 24 human cervical spine vertebrae (C3-6) from 6 fresh-frozen cadaver specimens from donors whose mean age was $84.3 \pm 10.4$ years at death. For each vertebra, one side was chosen randomly for PVFS and the other for LMS. For PVFS, a 3.2-mm drill with a stopper was advanced under lateral fluoroscopic imaging. The drill stopper was set to $12 \mathrm{~mm}$, which was considered sufficiently short not to breach the transverse foramen. The drill was directed from $20^{\circ}$ to $25^{\circ}$ medially so that the screw could purchase the relatively hard cancellous bone around the entry zone of the pedicle. The hole was tapped and a $4.5-\mathrm{mm}$-diameter $\times 12-\mathrm{mm}$ screw was inserted. For LMS, 3.5-mm-diameter $\times 14-\mathrm{mm}$ screws were inserted into the lateral mass of C3-6. The pullout strength of each screw was measured. After pullout testing of LMS, a drill was inserted into the screw hole and the superior cortex of the lateral mass was pried to cause a fracture through the screw hole, simulating intraoperative fracture of the lateral mass. After the procedure, PVFS for salvage (sPVFS) were inserted on the same side and pullout strength was measured.

RESULTS The CT scans obtained after screw insertion revealed no sign of pedicle breaching, violation of the transverse foramen, or fracture of the lateral mass. A total of 69 screws were tested (23 PVFS, 23 LMS, and 23 sPVFS). One vertebra was not used because of a fracture that occurred while the specimen was prepared. The mean bone mineral density of the specimens was $0.29 \pm 0.10 \mathrm{~g} / \mathrm{cm}^{3}$. The mean pullout strength was $234 \pm 114 \mathrm{~N}$ for PVFS, $158 \pm 91 \mathrm{~N}$ for LMS, and $195 \pm 125 \mathrm{~N}$ for sPVFS. The pullout strength for PVFS tended to be greater than that for LMS. However, the difference was not quite significant $(p=0.06)$.

CONCLUSIONS The authors introduce a novel fixation technique for the subaxial cervical spine. This study suggests that PVFS tend to provide stronger fixation than LMS for initial applications and fixation equal to LMS for salvage applications. If placement of LMS fails, PVFS can serve as a salvage fixation technique.

https://thejns.org/doi/abs/10.3171/2016.12.SPINE16803

KEY WORDS paravertebral foramen screw; lateral mass screw; pedicle screw; biomechanical study; pullout strength; cervical spine; surgical technique

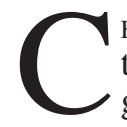
ERVICAL posterior fusion surgery with instrumentation is a widely accepted treatment for pathologies such as trauma, degenerative disease, tumor, inflammatory disease, and deformity. There are 2 fixation techniques commonly used in the subaxial cervical spine: pedicle screws (PS) and lateral mass screws (LMS). Each technique has its advantages and disadvantages. On the one hand, PS provide the strongest anchor in cervical fusion surgery, although they present a potential risk of vertebral artery injury, which can be a catastrophic

ABBREVIATIONS BMD = bone mineral density; LMS = lateral mass screws; $P S$ = pedicle screws; PVFS = paravertebral foramen screws; SPVFS = PVFS for salvage; VBMD = volumetric BMD.

SUBMITTED July 5, 2016. ACCEPTED December 15, 2016

INCLUDE WHEN CITING Published online May 12, 2017; DOI: 10.3171/2016.12.SPINE16803. 

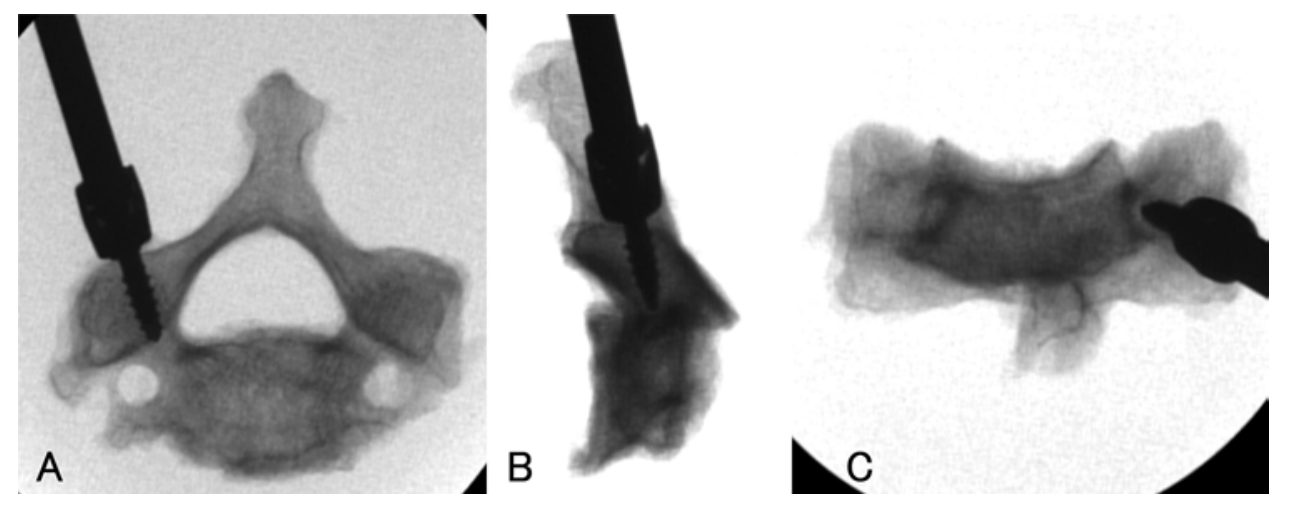

FIG. 1. Axial (A), lateral (B), and anteroposterior (C) fluoroscopic views of PVFS inserted in vertebrae.

complication..$^{21,22,24,28}$ On the other hand, placing LMS is a relatively safe method with a lower incidence of fatal complications compared with the use of PS, although LMS have a weaker primary stability than that obtained by PS, possibly resulting in inadequate fixation in patients with osteoporosis. ${ }^{7,9,29}$

Aramomi et al. ${ }^{3}$ proposed a novel technique for subaxial cervical fusion surgery using paravertebral foramen screws (PVFS). The trajectory of the screw is similar to that of a pars screw or short PS, but unique in the point that it uses a short wide screw with its thread purchasing relatively hard cancellous bone around the lateral border of the vertebral foramen (i.e., the spinal canal). Using screws short enough not to breach the transverse foramen, placement of PVFS is theoretically a safe technique. Although we assume that the biomechanical strength of PVFS could be equal or greater than that of LMS, its actual biomechan-

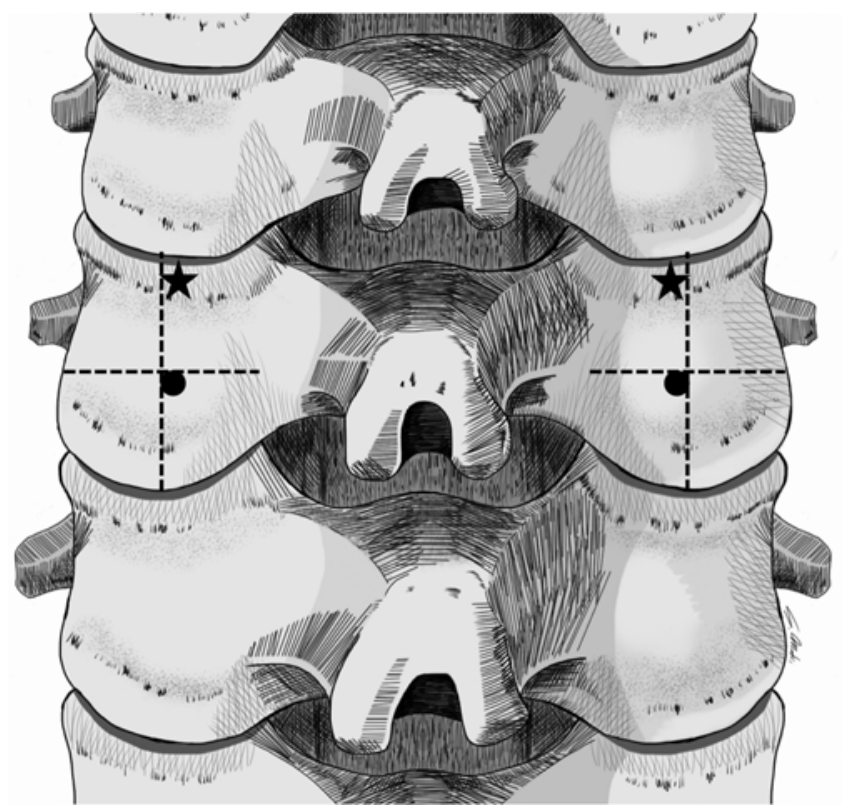

FIG. 2. Illustration of the posterior subaxial cervical spine showing the location of the starting points for each screw. The starting points for the PVFS are shown as stars. The starting points for the sPVFS are the same as those or 1-2 mm medial to those of the primary starting points. The starting points for the LMS are shown as black dots. Copyright Satoshi Maki. Published with permission. ical strength is unknown. We are also interested in whether PVFS could be used as a salvage fixation for failed LMS because the drill, tap, or screw used for insertion of LMS occasionally causes fracture of the lateral mass.

A biomechanical study of spinal fusion performed with PVFS was conducted to determine its primary stability. We describe placement of PVFS for subaxial cervical spine fusion surgery as a novel technique that is considered to be biomechanically stable. The suitability of PVFS as salvage for a fractured lateral mass was also determined.

\section{Methods}

\section{Surgical Technique}

On preoperative $\mathrm{CT}$ scans we determined that the length of the screw was $0-1 \mathrm{~mm}$ shorter than the distance from the surface of the lateral mass to the transverse foramen (Fig. 1). The cervical spine was exposed subperiosteally to the lateral edge of the lateral mass. The starting point was made with a 2-mm-deep speed bur at $1 \mathrm{~mm}$ medial to the cross-point of the midline of the lateral mass and the inferior margin of the inferior articular process of the cranially adjacent vertebra (Fig. 2). A 3.2-mm drill with a planned length stopper was advanced under lateral fluoroscopic imaging. The drill was directed from $20^{\circ}$ to $25^{\circ}$ medially so that the screw could purchase relatively hard cancellous bone at the entry zone of the pedicle. ${ }^{2}$ The hole was tapped and palpated with a ball tip probe to ensure intact walls, and a 4.5-mm-diameter polyaxial screw was inserted. There was no difference in the starting points or directions of the screws at the various vertebral levels on CT measurements in 30 preoperative patients (Table 1).

\section{Specimen Preparation}

We harvested 24 human cervical spine vertebrae (C36) from 6 fresh-frozen cadaver specimens (4 male and 2 female), whose donors' mean age at death was $84.3 \pm 10.4$ years, obtained from our university's Clinical Anatomy Laboratory. Signed informed consent had been obtained before cadaver donation for all specimens used. Only specimens that had no evidence of infection, trauma, or malignancy in the cervical spine were used. All specimens were inspected by CT (Eclos, Hitachi; $120 \mathrm{kV}, 200 \mathrm{~mA}$ ) to exclude any preexisting fracture or deformity.

To prepare specimens for biomechanical testing, the 
TABLE 1. Direction of the PVFS at various cervical vertebral levels

\begin{tabular}{cc}
\hline Vertebral Level & Medial Angle of the Screw $\left({ }^{\circ}\right)$ \\
\hline C-3 & $20.7 \pm 5.7$ \\
\hline C-4 & $22.6 \pm 4.8$ \\
\hline C-5 & $24.3 \pm 4.6$ \\
\hline C-6 & $23.0 \pm 6.1$ \\
\hline
\end{tabular}

The medial angle of the insertion of PVFS for each vertebra was measured during the preoperative planning for the 30 patients. There was no statistical difference in the angles of the screws at the various vertebral levels. Values are expressed \pm SD.

spines were thawed at room temperature and all surrounding soft tissue was removed. During preparation and testing, specimens were kept moist with a saline solution spray.

\section{Volumetric Bone Mineral Density}

Volumetric bone mineral density (vBMD) measurements of the lateral mass were obtained by quantitative $\mathrm{CT}$ of each vertebra, using a software package (Mechanical Finder; Research Center for Computational Mechanics, Tokyo). A $5.0 \times 5.0 \times 5.0-\mathrm{mm}$ cubic region of interest was defined in the center of each lateral mass in a 3D model and its vBMD was measured (Fig. 3).

\section{Instrumentation Tested}

For each vertebra, one side was chosen randomly for PVFS and the other for LMS. Thus, each vertebra served as its own internal control, reducing variability because of bone quality. The instrumentation used was a Synapse system from DePuy Synthes Spine. Because the cervical spine was dissected into single vertebrae, we were able to have direct visual inspection of the pedicle and lateral mass. For tests of PVFS, 4.5-mm-diameter $\times 12$-mm screws were inserted in the manner described above. For LMS, the starting point was made with a 2-mm bur at the center of the lateral mass (Fig. 2). Screw holes were drilled with a $2.5-\mathrm{mm}$ drill bit with a $14-\mathrm{mm}$ depth stopper directed $25^{\circ}$ laterally in the axial plane and $45^{\circ}$ cranially in the sagittal plane. The 3.5 -mm-diameter $\times 14$-mm screws were inserted into the lateral mass of C3-6 vertebrae by using a modification of Magerl's technique.,13,27 The LMS did not have bicortical purchase to avoid interdigitation with resin
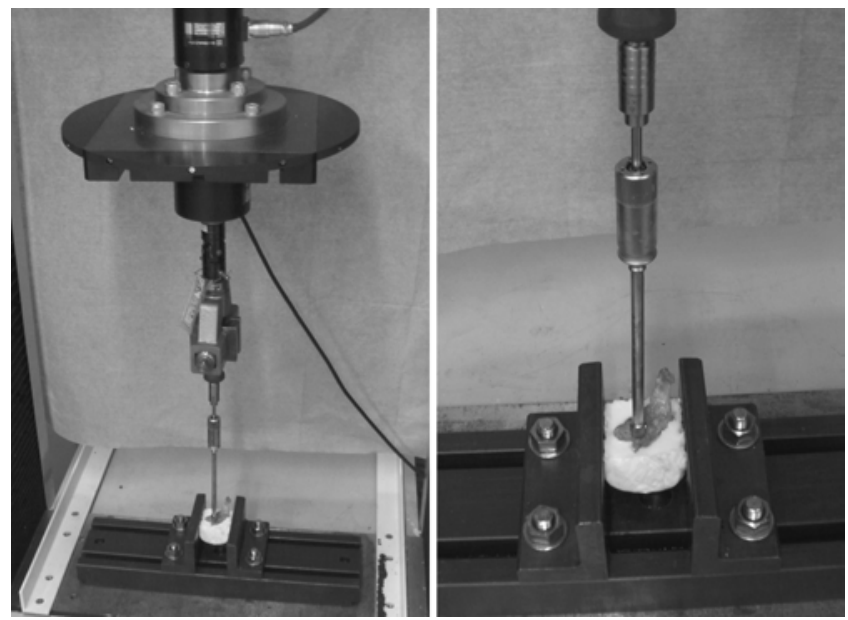

FIG. 4. Photographs of the pullout strength test setup. A half-dissected vertebra instrumented with a screw is embedded in resin, aligning the long axis of the screw with true axial pullout, and clamped in a testing machine. The screw head is securely attached to the screwdriver tip with a holding sleeve. The screwdriver is clamped to the ram of the testing machine. All screws were pulled out in the direction of the screw axis, and the pullout strength was recorded.

cement for fixing vertebrae to a universal testing machine. After inserting screws, we used CT to check their position in the specimens. All of the screws were placed by a fellowship-trained spine surgeon, who is well experienced in the field of cervical spine surgery.

\section{Pullout Strength Testing}

The pullout strength of each screw was measured using an Autograph DCS-2000 universal testing machine (Shimadzu). The C3-6 vertebrae were isolated and bisected at the center of the laminae and vertebral body. Subsequently, specimens were embedded in polyurethane resin cement (Wave) so that the axis of the screw was aligned with the true axial pullout. The screws were pulled out in line with the axis of their trajectory at $2.5 \mathrm{~mm}$ per minute. The peak load was measured (Fig. 4).

\section{Salvage of Failed LMS}

After pullout testing of LMS, a drill was put into the screw hole and the superior cortex of the lateral mass was
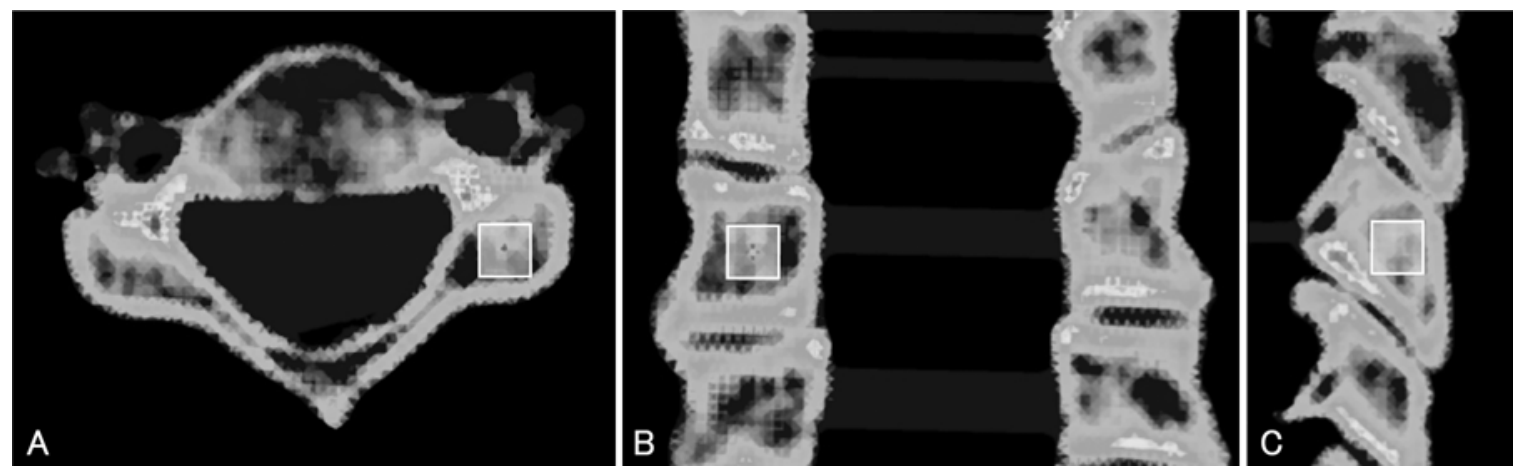

FIG. 3. Axial (A), coronal (B), and sagittal (C) views of a 3D model obtained by quantitative CT. We measured the vBMD of a $5.0 \times$ $5.0 \times 5.0-\mathrm{mm}$ cubic region of interest shown here in the center of the lateral mass. 


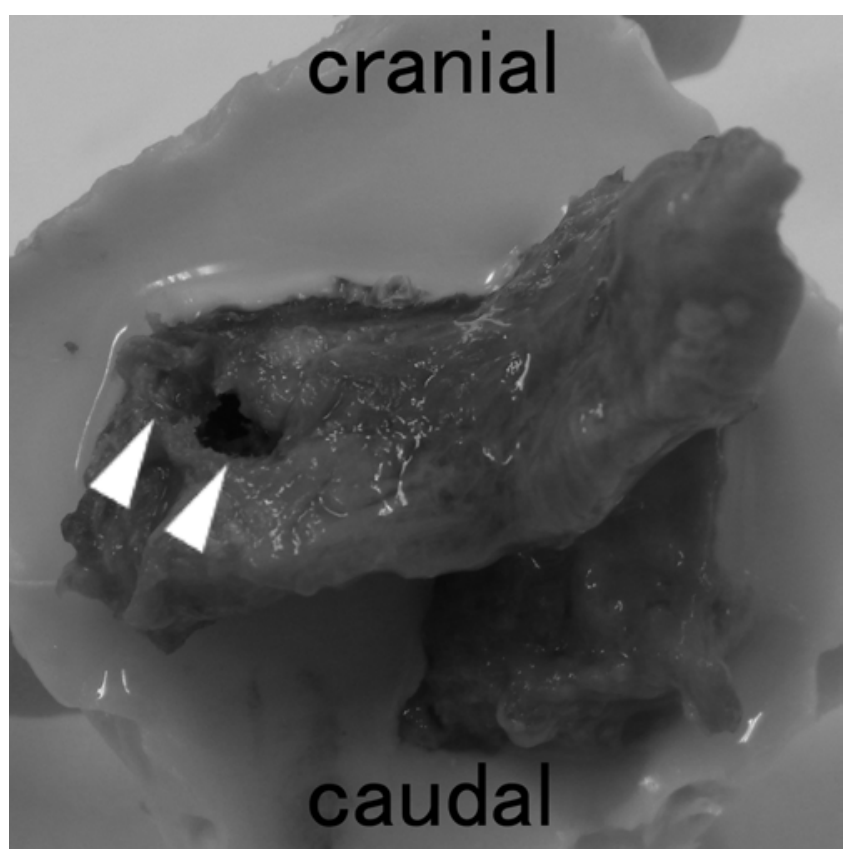

FIG. 5. Photograph of the left side of a half-dissected vertebra. Fracture of the superior cortex of a lateral mass (white arrowheads) is made to simulate intraoperative fracture of the lateral mass and stripping of the screw.

pried to cause a fracture through the screw hole (Fig. 5). This method was used to simulate both intraoperative fracture of the lateral mass and stripping of the screw. After the procedure, PVFS for salvage (sPVFS) were inserted on the same side and pullout strength was measured. The starting point for sPVFS was the same as for PVFS, or 1-2 mm medial to that of PVFS where the fracture line of the lateral mass was close to the starting point (Fig. 2).

\section{Statistical Analysis}

Differences in pullout strength between the PVFS, LMS, and sPVFS were compared using a Tukey-Kramer test. The correlation between pullout strength and vBMD was determined using Pearson's coefficient; $p<0.05$ was considered significant. All the analyses were conducted using JMP version 10.0.2 (SAS Institute).

\section{Results}

The CT scans obtained after screw insertion revealed no sign of pedicle breaching, violation of the transverse foramen, or fracture of a lateral mass for the total of 69 screws tested (23 PVFS, 23 LMS, and 23 sPVFS). One vertebra was not used because of a fracture that occurred while the specimen was prepared.

The mean vBMD of the specimens was $0.29 \pm 0.10$ $\mathrm{g} / \mathrm{cm}^{3}$. The mean vBMD of the lateral mass of PVFS was $0.31 \pm 0.11 \mathrm{~g} / \mathrm{cm}^{3}$ and the mean vBMD of the LMS or sPVFS side was $0.28 \pm 0.10 \mathrm{~g} / \mathrm{cm}^{3}$. The mean pullout strength was $234 \pm 114 \mathrm{~N}$ for the PVFS, $158 \pm 91 \mathrm{~N}$ for the LMS, and $195 \pm 125 \mathrm{~N}$ for the sPVFS. The pullout strength of the PVFS tended to be greater than that of the LMS; however, the difference was not quite significant ( $\mathrm{p}$ $=0.06$; Fig. 6). The vBMD was strongly correlated with

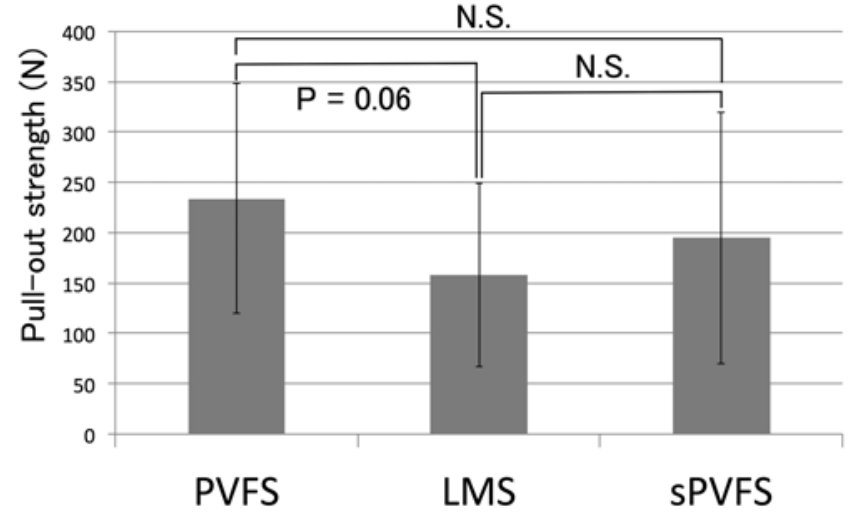

FIG. 6. Bar graph showing the mean pullout strength of PVFS, LMS, and SPVFS. Error bars represent the standard deviation. N.S. = not significant.

the pullout strength of PVFS, and moderately correlated with the pullout strength of LMS and sPVFS (Fig. 7).

\section{Discussion}

In the present report, we describe a novel technique as an alternative method for fixation of the subaxial cervical spine. The present study demonstrated that PVFS tended to have a greater pullout strength than LMS, although the difference was not quite significant. Furthermore, PVFS can be used for salvage applications if the lateral mass is fractured during insertion of LMS.

Use of PVFS can provide increased stability, thereby allowing for a higher fusion rate. Previous studies have indicated that PS have a greater initial strength than LMS during a plain axial pullout test, and even after uniplanar cyclic loading, the greater pullout strength of PS compared with LMS was maintained..$^{12,14,15,17}$ That is, the mean pullout strength was 636-696 N for PS and 231-382 N for LMS according to the Magerl technique described in previous reports. ${ }^{4,9,11,14,15,17}$ We found that the pullout strength of LMS was less than that found in previous studies. This can be attributed to the extremely old age and Asian ethnicity of the people providing the cadaver specimens we used; the donors tended to have osteoporosis. Another reason for the smaller pullout strength for LMS can be monocortical purchase of the LMS, which was intended to avoid screw intrusion into resin cement. Bicortical purchase provides a greater pullout strength for LMS, with a gain of $28 \%$ compared with monocortical purchase. ${ }^{9}$ However, it remains unclear whether this amount of enhanced purchase justifies the risk of nerve root injury associated with bicortical purchase. ${ }^{9}$

Taking this background into consideration, we assume that PVFS have a primary stability that is intermediate between PS and LMS. There is significant variation in cervical spine $\mathrm{vBMD}$ with respect to anatomical location. ${ }^{2}$ The average BMD of the pedicles is $15 \%$ more than the laminae and lateral masses. Considering that the pullout strength of both PVFS and LMS has been well correlated with VBMD, the greater pullout strength of PVFS can be attributed to the significant difference between the pedicle and lateral mass BMD, due to the purchase of the tip of the PVFS on part of the pedicle. Furthermore, it is gener- 

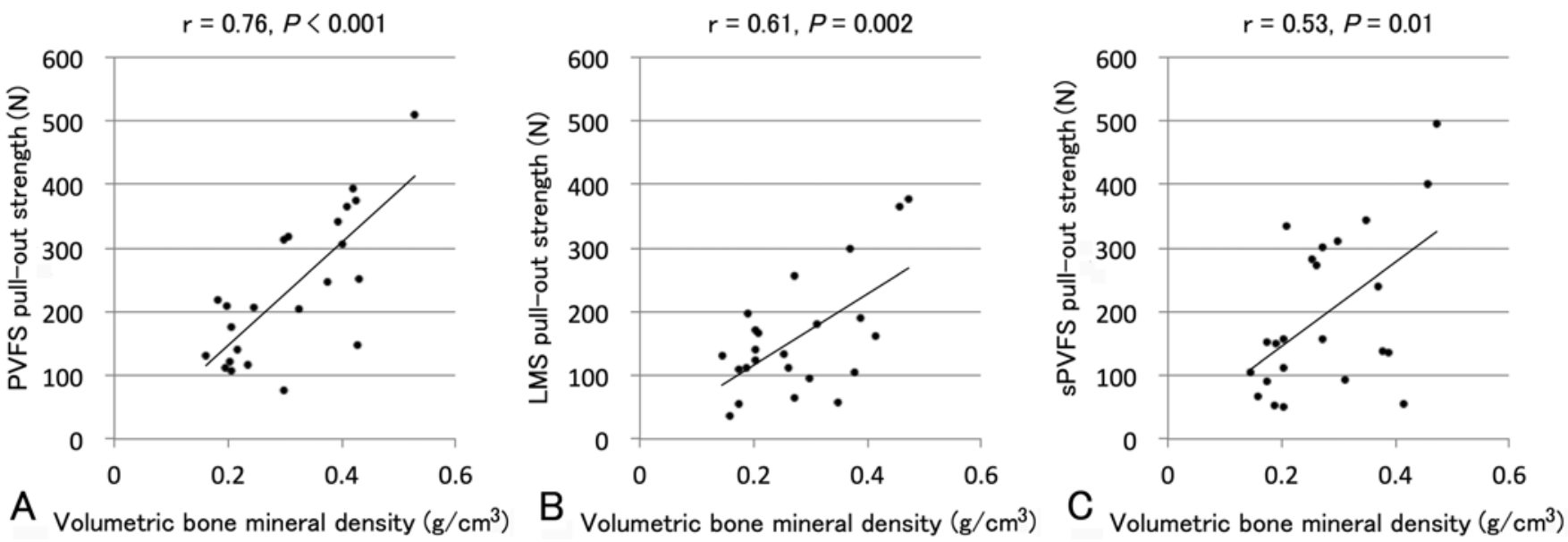

FIG. 7. Scatterplots showing Pearson correlations between pullout strength for each screw and vBMD.

ally accepted that the diameter of the screw has a positive impact on pullout strength.,29 The larger diameter of the PVFS may contribute to their greater pullout strength compared with that of LMS. We used wider screws for PVFS to obtain stronger fixation and overcome the shortcomings of using short screws that were intended to avoid violation of the transverse foramen. There was sufficient bony space for PVFS, whereas for LMS there is not.

The PVFS can be used in salvage applications in case of failure of placement of LMS. Occasionally, we fail to place LMS because of fracture of the lateral mass during screw insertion or pulling out of a screw when it is reduced to a rod. This requires us to attempt a different fixation method at that level to salvage the failed screw or to extend fixation to an additional level. To date, candidates for salvage of failed LMS are PS or a larger-diameter LMS (Magerl and Roy-Camille techniques). Conversion to PS is a salvage option and can be expected to provide better fixation. However, conversion to PS is technically demanding, and application of PS to a narrow pedicle or dominant side of the vertebral artery should be avoided. ${ }^{11}$ Larger-diameter LMS can also be used as salvage for stripped screws, but is not suitable for a catastrophically fractured lateral mass. ${ }^{11,20}$ The PVFS can be used to salvage failed LMS because even in the case of a lateral mass fracture, the middle to upper quadrant of the lateral mass where the PVFS are to be inserted is preserved. Our results demonstrated that sPVFS have as strong a primary stability as primary LMS. Thus, PVFS can be an option for rescuing failed LMS. Moreover, PVFS can be easily placed in line with LMS and easily connected to PS by using a rod.

Consistent with previous reports, we found a correlation between screw pullout strength and intrapedicular BMD. ${ }^{10,25,30}$ There are studies that found no significant correlation between LMS pullout strength and BMD.,9 This may be the result of evaluating the BMD of the vertebral body and not the BMD of the segment where the screws were inserted.

There are several limitations to the present study. First, pullout is considered the standard testing method because there is a vast historical database of test results; however, it is not clear that pullout accurately reflects the clinical setting because, as a clinical mode of failure, pullout is rare..$^{8,19,23}$ Toggling fatigue loading is considered to be more clinically relevant. ${ }^{6,16,18}$ Even more relevant may be tests of segments that are instrumented with entire assemblies of implants with 6 degrees of freedom loading. ${ }^{26}$ Nevertheless, we used a pullout test because it is a relatively easy and consistent test with which to assess the new screw method, and because a standardized testing method has been established (American Society for Testing and Materials, F543). Second, because of the limited availability of cadaver specimens, relatively small numbers of specimens were used, narrowing the statistical power of the study and allowing interspecimen variability, which leads to large standard deviations in BMD, and results in a relatively large standard deviation in pullout strength of the screws. However, we compared the screws on the left and right sides of the same vertebrae to serve as their own internal controls. Third, placement of PVFS requires fluoroscopic imaging guidance, although placement of LMS can be achieved without fluoroscopic imaging. Despite these limitations, our findings indicate biomechanical advantages of PVFS over LMS and may justify their use in clinical settings. Moreover, should fixation with LMS fail, PVFS can be used as an option for salvage. Thus, placement of PVFS is an option for optimal anchoring in subaxial cervical spine fusion surgery.

\section{Conclusions}

In the present report we introduce a novel fixation technique for the subaxial cervical spine. Our findings suggest that PVFS tend to provide stronger fixation than LMS for initial applications and fixation equal to LMS for salvage applications. If the placement of LMS fails, placement of PVFS can serve as a salvage fixation technique.

\section{Acknowledgments}

We thank Takayuki Tanaka for assistance in working on the tool (shaping the handle of the screwdriver) used in this study.

\section{References}

1. An HS, Gordin R, Renner K: Anatomic considerations for 
plate-screw fixation of the cervical spine. Spine (Phila Pa 1976) 16 (10 Suppl):S548-S551, 1991

2. Anderst WJ, Thorhauer ED, Lee JY, Donaldson WF, Kang JD: Cervical spine bone mineral density as a function of vertebral level and anatomic location. Spine J 11:659-667, 2011

3. Aramomi M, Ishikawa T, Maki S: [Paravertebral foramen screw fixation for posterior cervical spine surgery.] J Spine Res 5:549, 2014 (Jpn)

4. Barrey C, Mertens P, Rumelhart C, Cotton F, Jund J, Perrin G: Biomechanical evaluation of cervical lateral mass fixation: a comparison of the Roy-Camille and Magerl screw techniques. J Neurosurg 100 (3 Suppl Spine):268-276, 2004

5. Chapman JR, Harrington RM, Lee KM, Anderson PA, Tencer AF, Kowalski D: Factors affecting the pullout strength of cancellous bone screws. J Biomech Eng 118:391-398, 1996

6. Choma TJ, Pfeiffer FM, Swope RW, Hirner JP: Pedicle screw design and cement augmentation in osteoporotic vertebrae: effects of fenestrations and cement viscosity on fixation and extraction. Spine (Phila Pa 1976) 37:E1628-E1632, 2012

7. Coe JD, Vaccaro AR, Dailey AT, Skolasky RL Jr, Sasso RC, Ludwig SC, et al: Lateral mass screw fixation in the cervical spine: a systematic literature review. J Bone Joint Surg Am 95:2136-2143, 2013

8. Esses SI, Sachs BL, Dreyzin V: Complications associated with the technique of pedicle screw fixation. A selected survey of ABS members. Spine (Phila Pa 1976) 18:2231-2239, 1993

9. Heller JG, Estes BT, Zaouali M, Diop A: Biomechanical study of screws in the lateral masses: variables affecting pullout resistance. J Bone Joint Surg Am 78:1315-1321, 1996

10. Hirano T, Hasegawa K, Takahashi HE, Uchiyama S, Hara T, Washio T, et al: Structural characteristics of the pedicle and its role in screw stability. Spine (Phila Pa 1976) 22:25042510, 1997

11. Hostin RA, Wu C, Perra JH, Polly DW, Akesen B, Wroblewski JM: A biomechanical evaluation of three revision screw strategies for failed lateral mass fixation. Spine (Phila Pa 1976) 33:2415-2421, 2008

12. Ito Z, Higashino K, Kato S, Kim SS, Wong E, Yoshioka K, et al: Pedicle screws can be 4 times stronger than lateral mass screws for insertion in the midcervical spine: a biomechanical study on strength of fixation. J Spinal Disord Tech 27:80-85, 2014

13. Jeanneret B, Magerl F, Ward EH, Ward JC: Posterior stabilization of the cervical spine with hook plates. Spine (Phila Pa 1976) 16 (3 Suppl):S56-S63, 1991

14. Johnston TL, Karaikovic EE, Lautenschlager EP, Marcu D: Cervical pedicle screws vs. lateral mass screws: uniplanar fatigue analysis and residual pullout strengths. Spine $\mathbf{J}$ 6:667-672, 2006

15. Jones EL, Heller JG, Silcox DH, Hutton WC: Cervical pedicle screws versus lateral mass screws. Anatomic feasibility and biomechanical comparison. Spine (Phila Pa 1976) 22:977-982, 1997

16. Kiner DW, Wybo CD, Sterba W, Yeni YN, Bartol SW, Vaidya $\mathrm{R}$ : Biomechanical analysis of different techniques in revision spinal instrumentation: larger diameter screws versus cement augmentation. Spine (Phila Pa 1976) 33:2618-2622, 2008

17. Kowalski JM, Ludwig SC, Hutton WC, Heller JG: Cervical spine pedicle screws: a biomechanical comparison of two insertion techniques. Spine (Phila Pa 1976) 25:2865-2867, 2000

18. Kueny RA, Kolb JP, Lehmann W, Püschel K, Morlock MM, Huber G: Influence of the screw augmentation technique and a diameter increase on pedicle screw fixation in the osteoporotic spine: pullout versus fatigue testing. Eur Spine J 23:2196-2202, 2014

19. Lee TC: Complications of transpedicular reduction and sta- bilization of the thoracolumbar spine. J Formos Med Assoc 94:738-741, 1995

20. Lovick DS, Ryken TC, Traynelis VC, Dexter F: Assessment of primary and salvage lateral mass screw insertion torque in a cadaveric model. J Spinal Disord 10:431-435, 1997

21. Madawi AA, Casey AT, Solanki GA, Tuite G, Veres R, Crockard HA: Radiological and anatomical evaluation of the atlantoaxial transarticular screw fixation technique. J Neurosurg 86:961-968, 1997

22. Mandel IM, Kambach BJ, Petersilge CA, Johnstone B, Yoo $\mathrm{JU}$ : Morphologic considerations of $\mathrm{C} 2$ isthmus dimensions for the placement of transarticular screws. Spine (Phila Pa 1976) 25:1542-1547, 2000

23. Ohlin A, Karlsson M, Düppe H, Hasserius R, RedlundJohnell I: Complications after transpedicular stabilization of the spine. A survivorship analysis of 163 cases. Spine (Phila Pa 1976) 19:2774-2779, 1994

24. Wakao N, Takeuchi M, Nishimura M, Riew KD, Kamiya M, Hirasawa A, et al: Vertebral artery variations and osseous anomaly at the C1-2 level diagnosed by 3D CT angiography in normal subjects. Neuroradiology 56:843-849, 2014

25. Wichmann JL, Booz C, Wesarg S, Bauer RW, Kerl JM, Fischer S, et al: Quantitative dual-energy CT for phantomless evaluation of cancellous bone mineral density of the vertebral pedicle: correlation with pedicle screw pull-out strength. Eur Radiol 25:1714-1720, 2015

26. Wilke HJ, Kaiser D, Volkheimer D, Hackenbroch C, Püschel $\mathrm{K}$, Rauschmann M: A pedicle screw system and a lamina hook system provide similar primary and long-term stability: a biomechanical in vitro study with quasi-static and dynamic loading conditions. Eur Spine J 25:2919-2928, 2016

27. Wu JC, Huang WC, Chen YC, Shih YH, Cheng H: Stabilization of subaxial cervical spines by lateral mass screw fixation with modified Magerl's technique. Surg Neurol 70 (Suppl 1):S25-S33, 2008

28. Yamazaki M, Okawa A, Furuya T, Sakuma T, Takahashi H, Kato K, et al: Anomalous vertebral arteries in the extra- and intraosseous regions of the craniovertebral junction visualized by 3-dimensional computed tomographic angiography: analysis of 100 consecutive surgical cases and review of the literature. Spine (Phila Pa 1976) 37:E1389-E1397, 2012

29. Yoshihara H, Passias PG, Errico TJ: Screw-related complications in the subaxial cervical spine with the use of lateral mass versus cervical pedicle screws: a systematic review. J Neurosurg Spine 19:614-623, 2013

30. Zhang QH, Tan SH, Chou SM: Investigation of fixation screw pull-out strength on human spine. J Biomech 37:479-485, 2004

\section{Disclosures}

Dr. Takahashi received research funding that is not related to this study from DePuy Synthes, a Johnson \& Johnson Company.

\section{Author Contributions}

Conception and design: Koda, Maki, Aramomi, Matsuura, Furuya, Mannoji. Acquisition of data: Maki. Analysis and interpretation of data: Maki, Matsuura. Drafting the article: Maki. Critically revising the article: Koda, Aramomi, Matsuura. Reviewed submitted version of manuscript: Furuya, Ota, Iijima, Saito, Suzuki, Mannoji, Takahashi, Yamazaki. Administrative/ technical/material support: Ota, Iijima, Saito, Suzuki. Study supervision: Koda, Takahashi, Yamazaki.

\section{Correspondence}

Masao Koda, Department of Orthopaedic Surgery, Chiba University Graduate School of Medicine, 1-8-1 Inohana, Chuou-ku, Chiba 260-8670, Japan. email: masaokod@gmail.com. 